\title{
BMJ Open Depression and its correlation with social support and health-promoting lifestyles among Chinese university students: a cross-sectional study
}

\author{
Zaili Tang (D) , ${ }^{1}$ Shuidong Feng, ${ }^{2}$ Jing Lin $^{3}$
}

To cite: Tang Z, Feng S, Lin J. Depression and its correlation with social support and healthpromoting lifestyles among Chinese university students: a cross-sectional study. BMJ Open 2021;11:e044236. doi:10.1136/ bmjopen-2020-044236

- Prepublication history for this paper is available online. To view these files, please visit the journal online (http://dx.doi. org/10.1136/bmjopen-2020044236).

Received 01 September 2020 Accepted 10 June 2021
Check for updates

(C) Author(s) (or their employer(s)) 2021. Re-use permitted under CC BY-NC. No commercial re-use. See rights and permissions. Published by BMJ.

${ }^{1}$ Department of Medical Record Management and Statistics, First Affiliated Hospital of University of South China, Hengyang, China ${ }^{2}$ Department of Epidemiology \& Health Statistics, University of South China, Hengyang, China

${ }^{3}$ Xiangya International Academy of Translational Medicine, Central South University, Changsha, China

Correspondence to

Shuidong Feng;

shuidong_f@hotmail.com

\section{ABSTRACT}

Objectives To investigate the prevalence of depression in college students and determine how social support and healthy lifestyle factors are associated with depression in this population.

Design A cross-sectional design.

Setting A comprehensive university in Changsha, Hunan, South China. The study was conducted from May to June 2019.

Participants A total of 541 students at the comprehensive university.

Primary and secondary outcome measures The Zung Self-Rating Depression Scale, Social Support Rating Scale and Health-Promoting Lifestyle Profile-II (HPLP-II) were used to evaluate depression, social support and lifestyles, respectively, and analyse the mutual relationships among them.

Results Among the 541 participants, 161 (29.8\%) experienced depressive symptoms, and there were significant gender-related and academic discipline-related differences in self-rated depression. The average social support score was $38.06(38.06 \pm 7.52)$. The average HPLPII score was 71.09 (71.09 \pm 11.47$)$. A monofactor analysis showed that depression was correlated with social support and a healthy lifestyle. As demonstrated by logistic regression analysis, being a woman $(0 \mathrm{R}=2.613,95 \% \mathrm{Cl}$ : 1.541 to 4.43 ), inadequate social support (OR=0.912, $95 \% \mathrm{Cl}: 0.877$ to 0.948$)$, poor nutrition (OR=0.87, $95 \% \mathrm{Cl}$ : 0.775 to 0.977$)$ and lack of self-actualisation $(\mathrm{OR}=0.644$, $95 \% \mathrm{Cl}: 0.572$ to 0.724$)$ were significantly correlated with depression.

Conclusions Owing to the high prevalence of depression among Chinese university students, educational institutions must take measures such as providing compulsory mental health education courses and improving the psychological counselling services available to students.

\section{INTRODUCTION}

Depression, one of the most common psychological diseases, has become a major risk factor affecting physical and psychological health. ${ }^{1}$ According to WHO statistics, globally, from 2005 to 2015, the number of people with depression increased by $18.4 \%$. Although >300 million people worldwide
Strengths and limitations of this study

- Multivariate analysis was used to determine the risk factors for depression, which can form the basis of future intervention research.

- Owing to the cross-sectional design, it was not possible to establish causality in the relationships between risk factors and depression.

- The small sample recruited from a single institution limits the generalisability of the results.

experience depression, in China alone, this number has been reported to be 54 million. ${ }^{2}$ Research has shown that depression is closely related to unhealthy lifestyles, ${ }^{3}$ physical illness, ${ }^{4}$ suicide $^{56}$ and disease burden. ${ }^{7-9}$

College students, who are in the transitional period from puberty to adulthood, are a special group because they begin to face problems in various aspects, for example, issues in interpersonal relationships, academic pressure and financial difficulties, which they must face independently and make important life decisions. Psychological problems in this population are significant. Many studies have indicated that depression is the most widespread psychological disease among college students, with a prevalence of about $30 \%$ regardless of peacetime or public health emergencies like the COVID-19 pandemic. ${ }^{6}$ 10-15 Although a recent study reported a depression rate of $69.2 \%$ during the COVID-19 pandemic, ${ }^{16}$ its small sample size hinders the generalisability of the findings. Overall, about $1.0 \%-4.0 \%$ of college students experience severe depression, ${ }^{11} 17$ which seriously affects various aspects of their lives, including academic performance and social function. ${ }^{18}$

As demonstrated by extensive previous research, the high depression prevalence among college students is related to their demographic characteristics. ${ }^{6} 1719$ Studies have also 
shown that depression is related to the quality and quantity of social support, ${ }^{180-26}$ which is an external protective factor for psychological diseases. ${ }^{27}$ Early in the 1970 s, the concept of social support was introduced in the psychiatric, sociologicaland medical literature, with researchers extensively examining the relationship between social support and physical and mental health using quantitative evaluation methods. ${ }^{28} 29$ These researchers believed that good social support is beneficial to health, while bad social relationships are harmful to physical and mental health. For example, one study confirmed that loneliness and a perceived lack of emotional support had the largest and most consistent associations across depression outcomes, with incidence rates of 1.55-9.97 and 1.23-1.40, respectively. ${ }^{30}$ A recent study showed that students with poor social support, such as those who independently bore a large financial burden, lived alone or had poor relationships with their lovers, classmates or friends, had higher depression scores. ${ }^{31}$ Based on the previous studies, we believe that social support is an indispensable factor in the study of depression.

A health-promoting lifestyle is one in which selfinitiated, continuous, daily activity is undertaken with the deliberate aim of increasing or promoting health and wellbeing. ${ }^{32}$ In a study by the WHO, lifestyle and social support played a key role in health. ${ }^{33}$ Many recent studies have found that healthy lifestyles could reduce the incidence of depression in different groups, such as people with chronic illnesses, puerperae and older adults, ${ }^{32}{ }^{34-37}$ who, because of their psychological vulnerability, generally lack the ability to take care of themselves; in this regard, they are similar to college students. The latest research shows that the cultivation of health-related behaviours may help in lowering depressive symptoms, which is related to unhealthy eating habits, inadequate exercise and sleep and prolonged computer exposure. ${ }^{38-40}$ However, few scholars have discussed the relationships between depression, social support and a series of individual health behaviours in college students. ${ }^{41}$ Considering that, based on the previous studies, the same indicator may differ across countries and cultures, ${ }^{42}{ }^{43}$ there is a lack of Chinaspecific reports on college students' health-promoting lifestyles and their association with depression.

Accordingly, this study investigates the prevalence rate of depression, degrees of social support, healthpromoting lifestyles and their relevance to provide a scientific basis for health education and intervention in college students' depression.

\section{METHODS}

This cross-sectional, descriptive, correlational study explored depression, degrees of social support, healthpromoting lifestyles and their relationships among college students in China.

\section{Patient and public involvement}

No patients or members of the public were involved in the design, execution, reporting or dissemination of this research.

\section{Research object}

The authors distributed self-administered questionnaires to students from a comprehensive university in Hunan Province, China, in May and June 2019.

\section{Sample}

The sample size was estimated according to the formula $\mathrm{N}=\mathrm{u}_{\alpha / 2}^{2} \Phi(1-\bar{\varpi}) / \delta^{2}$, which is commonly used in crosssectional epidemiological studies. Previous studies have estimated that the average prevalence of depression among college students in China is approximately $30 \%^{4445}$; therefore, $\varpi=30 \%$. If $\delta=0.05$ and $\alpha=0.05$, the estimated sample would be 323 participants; if $\delta=0.04$, the estimated sample would be 504 participants. We chose a larger sample size to ensure higher data accuracy. An additional 20\% sample size was added to ensure that students who chose not to participate in the survey were included; thus, the final sample size was estimated to be approximately 600 individuals.

A simple random sampling method was used, and investigators were required to ensure that the sample's demographic characteristics were relatively uniform. Part-time students were excluded. A total of 600 individuals were recruited, 545 of whom signed the consent form and completed the questionnaire. After excluding four questionnaires owing to missing data $(>5 \%), 541$ valid questionnaires were analysed (effective recovery rate $=90.17 \%$ ).

\section{Measures}

The self-administered questionnaire included questions on demographic characteristics (self-designed) and instruments to evaluate depression, social support and health-promoting lifestyles.

\section{Demographic section}

The demographic characteristics of interest included age, gender, grade, area of residence, only-child status and family income, which was assessed by the investigator and categorised as follows: $\leq ¥ 80000$ per year indicated a low income, $¥ 80000-¥ 300000$ indicated a medium income and $\geq ¥ 300000$ indicated a high income.

\section{Zung Self-Rating Depression cale}

The Zung Self-Rating Depression Scale (SDS) ${ }^{46}$ is a normreferenced measure used to screen adults for depressive disorders. It is widely used by Chinese researchers in the study of various populations ${ }^{47} 48$ and is suitable for college students. ${ }^{31}{ }^{49}$ The SDS includes 20 items, which are scored between 1 (never or very infrequently) and 4 (most or all of the time), and can intuitively reflect respondents' subjective feelings for nearly 1 week. The total score, ranging from 20 to 80 , can be converted to a standard score by multiplying it by 1.25. The higher the score, the more obvious the depression trend. A standard score $\geq 50$ is regarded as demonstrating the presence of depressive symptoms. ${ }^{46}$ Depression severity was determined by dividing the SDS score by 80 . Accordingly, participants were divided into the following four categories: those $<0.5$ were considered to have no symptoms of depression; those between 0.5 and 0.59 were assessed as having 
mild depression; those between 0.6 and 0.69 were assessed as having moderate-to-severe depression and those $>0.7$ were considered to have severe depression. ${ }^{46}$ The Cronbach's $\alpha$ coefficient of this scale was 0.905 .

\section{Social Support Rating cale}

The Social Support Rating Scale (SSRS), developed by Xiao, ${ }^{50}$ was used to measure the social support available to the participants. This instrument was specially designed for Chinese people and has high reliability $(\mathrm{r}=0.92){ }^{50}$ It comprises 10 items with three subscales (objective support, subjective support and utilisation of support) and is scored from 1 to 4 . The total score ranged between 11 and 64 . The higher the score, the higher the social support level. The Cronbach's $\alpha$ coefficient of this scale was 0.820 .

\section{Health-Promoting Lifestyle Profile-II}

The original Health-Promoting Lifestyle Profile (HPLP) was developed by Walker et $a \tilde{l}^{\tilde{1}}$ in 1987 and then revised to the HPLP-II, which is widely used with patients and healthy adults in the USA ${ }^{52-54}$ Although college students are adults, their context is specific to campus life; thus, some of the scale's items (such as those included under the nutrition dimension) are not applicable. Therefore, this study modified the Chinese version of the HPLP-II to suit the college context. The adapted instrument included 25 items and six subscales (interpersonal relationships, nutrition, health responsibility, physical activity, stress management and self-actualisation). The total score ranged between 25 and 100; the higher the score, the better the health-promoting lifestyle. The Cronbach's $\alpha$ coefficient of the overall scale was 0.914 , and the coefficients of the various subscales ranged from 0.772 to 0.895 , demonstrating excellent reliability and validity.

\section{Statistical analysis}

All the data were input into a computer, a database was established and SPSS V.18.0 software (SPSS) was used for statistical analysis. A descriptive analysis of the participants' basic information was undertaken, and a $\chi^{2}$ test and t-test were used to analyse the relationships between demographic characteristics, social support, healthy lifestyles and depression. Logistic regression was used to analyse the factors associated with depression. The level of statistical significant was set at $\mathrm{p}<0.05$ (two-tailed).

\section{RESULTS}

Among the 541 participants, 212 were men (39.2\%) and 329 were women $(60.8 \%)$. The sample's average age was 20.74 years (range $=15-38, \mathrm{SD}=2.55$ ). Specific information on the students' academic disciplines, year of study, place of residence and only-child status is shown in table 1 .

Among the 541 participants, the average SDS score was 34.99 ( $\mathrm{SD}=9.431$ ), ranging from 20 to 73. Specifically, 161 participants (29.8\%) demonstrated depressive symptoms,

\begin{tabular}{|c|c|c|c|}
\hline Variable & $\begin{array}{l}\text { Mean } \pm \text { SD/n } \\
(\%)\end{array}$ & Variable & n (\%) \\
\hline Age (years) & $20.74 \pm 2.55$ & Residence & \\
\hline Gender & & City & 297 (54.9) \\
\hline Men & 212 (39.2) & Country & $244(45.1)$ \\
\hline Women & $329(60.8)$ & Only child & \\
\hline Academic discipline & & Yes & $281(51.9)$ \\
\hline Medicine & $197(36.4)$ & No & $260(48.1)$ \\
\hline $\begin{array}{l}\text { Science and } \\
\text { engineering }\end{array}$ & 245 (45.3) & $\begin{array}{l}\text { Family } \\
\text { income }\end{array}$ & \\
\hline Art & 99 (18.3) & Low & $146(27.0)$ \\
\hline Year & & Medium & $375(69.3)$ \\
\hline First & 89 (16.5) & High & $20(3.7)$ \\
\hline Second & $256(47.3)$ & & \\
\hline Third & 70 (12.9) & & \\
\hline Fourth-fifth & $48(8.9)$ & & \\
\hline Postgraduate & 78 (14.5) & & \\
\hline
\end{tabular}

including 99 (18.3\%) with minor depression, 51 (9.4\%) with moderate depression and $11(2.0 \%)$ with severe depression.

Table 2 illustrates the relationship between participants' demographic characteristics and depression. The results showed that differences in self-rated depression by gender and discipline were statistically significant $(p<0.05)$. The prevalence of depression among medical students was significantly higher than among students from other disciplines $(\mathrm{p}<0.05)$, the same as women than men. That is, on the contrary, men than women, other disciplines such as art and science and engineering students than medical students were less likely to suffer depression $(\mathrm{p}<0.05)$.

The average SSRS score was 38.06 \pm 7.52 , ranging from 16 to 62 . One of the questions is the source of comfort and concern you received in an emergency: 43 students (7.9\%) said that they did not have any source, and 498 people chose one or more of them, including 455 (84.1\%) chose parents and relatives, $419(77.4 \%)$ chose classmates or friends, 198 chose lovers, $128(23.7 \%)$ chose teachers, $21(3.9 \%)$ chose psychological counsellors and $14(2.6 \%)$ chose other groups. The average HPLP-II score was 71.09 \pm 11.47 , ranging from 45 to 100 (table 3).

According to the analysis, participants who did not have depression had statistically significantly higher social support and health-promoting lifestyle scores (total scores as well as individual factor scores) than those with depression (both $\mathrm{p}<0.01)$. As shown by the results of the Pearson's correlation analysis, depression tendency had a significant negative correlation with the factor and total scores of the SSRS and HPLP-II $(\mathrm{p}<0.01)$, as shown in table 4.

Taking depression as the dependent variable and demographic characteristics and SSRS and HPLP-II factor and total scores as independent variables, further analysis was 
Table 2 Prevalence of depression by participants' demographic characteristics

\begin{tabular}{|c|c|c|c|c|}
\hline Variable & No depression (\%) & Depression (\%) & $\chi^{2}$ & $P$ value \\
\hline \multicolumn{5}{|l|}{ Age (years) } \\
\hline $20-22$ & $185(69.5 \%)$ & $81(30.5 \%)^{a}$ & & \\
\hline$>22$ & $58(63.0 \%)$ & $34(37.0 \%)^{\mathrm{a}}$ & & \\
\hline Women & $211(64.1 \%)$ & $118(35.9 \%)$ & & \\
\hline \multicolumn{5}{|l|}{ Discipline } \\
\hline Medicine & $118(59.9 \%)$ & $79(40.1 \%)^{a}$ & 15.985 & $<0.001$ \\
\hline Science and engineering & $188(76.7 \%)$ & $57(23.3 \%)^{b}$ & & \\
\hline Second & $178(69.5 \%)$ & $78(30.5 \%)^{a}$ & & \\
\hline Third & $50(71.4 \%)$ & $20(28.6 \%)^{a}$ & & \\
\hline Fourth-fifth & $32(66.7 \%)$ & $16(33.3 \%)^{a}$ & & \\
\hline Postgraduate & $49(62.8 \%)$ & $29(37.2 \%)^{a}$ & & \\
\hline \multicolumn{5}{|l|}{ Residence } \\
\hline City & $209(70.4 \%)$ & $297(29.6 \%)$ & 0.005 & 0.942 \\
\hline Country & $171(70.1 \%)$ & 244 (29.9\%) & & \\
\hline \multicolumn{5}{|l|}{ Only child } \\
\hline
\end{tabular}

Each superscript letter ( $\mathrm{a}$ or b) denotes a subset of the titled categories whose column proportions do not differ significantly from each other at the 0.05 level,but differ significantly from each other at the 0.05 level within two superscripts.

conducted by using a binary logistic regression model. According to the results, being a woman $(\mathrm{OR}=2.613,95 \% \mathrm{CI}$ : 1.541 to 4.43 ), inadequate social support $(\mathrm{OR}=0.912,95 \%$ CI: 0.877 to 0.948$)$, poor nutrition ( $\mathrm{OR}=0.87,95 \%$ CI: 0.775 to 0.977 ) and lack of self-actualisation ( $\mathrm{OR}=0.644,95 \% \mathrm{CI}$ : 0.572 to 0.724$)$ were significantly correlated with depression (table 5).

\section{DISCUSSION \\ Depression}

In recent years, depression has become the most common psychological disease among college students, with a rising annual incidence rate that significantly influences their learning and living and hinders their potential. ${ }^{55}$ This study demonstrated that depression is prevalent among Chinese college students: $29.8 \%$ of the participants experienced depressive symptoms. This result is in agreement with the findings of a systematic analysis from 2016, which reported a depression prevalence of $27.2 \%$ (95\% CI: $24.7 \%$ to $29.9 \%)^{6}$ across 43 countries, and a Chinese study from the same year, wherein the depression prevalence was $23.8 \%$ (95\% CI: $19.9 \%$ to $28.5 \%){ }^{56}$ This confirms that the present results reflect real-life scenarios.

As shown by our results, the possibility of female college students experiencing depression was 2.61 times higher than that of male students, slightly higher than what was reported in the previously mentioned meta-analysis based on the literature from multiple countries (1.95 times).$^{57}$ This result may have been caused by basic differences between men and women, such as with regard to physiological characteristics, social conditions and gender roles. ${ }^{2}$ According to a previous study, there are larger gender differences in major depression in nations with 
Table 3 Factor and total scores on the SSRS and HPLP-II $(\mathrm{N}=541)$

\begin{tabular}{lccc}
\hline Variable & Range of actual score (min-max) & Average score (mean \pm SD) & Percentage \\
\hline SSRS score & $16-62$ & $38.06 \pm 7.52$ & 0.61 \\
Objective support & $1-22$ & $8.67 \pm 3.16$ & 0.39 \\
Subjective support & $10-28$ & $20.68 \pm 3.91$ & 0.74 \\
Utilisation of support & $3-12$ & $8.71 \pm 2.92$ & 0.73 \\
HPLP-II score & $45-100$ & $71.91 \pm 11.47$ & 0.72 \\
Interpersonal relationships & $5-20$ & $14.62 \pm 3.43$ & 0.73 \\
Nutrition & $4-16$ & $11.61 \pm 2.53$ & 0.73 \\
Health responsibility & $7-16$ & $11.80 \pm 1.34$ & 0.74 \\
Physical activity & $4-16$ & $9.37 \pm 2.94$ & 0.59 \\
Stress management & $6-16$ & $11.80 \pm 2.44$ & 0.74 \\
Self-actualisation & $4-16$ & $12.72 \pm 2.74$ & 0.80 \\
\hline
\end{tabular}

HPLP-II, Health-Promoting Lifestyle Profile-II; SSRS, Social Support Rating Scale.

greater gender equality maybe because of fierce job competition. $^{57}$ China's government is pursuing such gender equality. ${ }^{58}$

Regarding academic disciplines, the prevalence of depression among medical students was $40.1 \%$, significantly higher than among students from other disciplines. This result is consistent with the range of $13.10 \%-76.21 \%$ reported in a systematic review of Chinese medical students, but higher than the average of $32.74 \% .{ }^{59}$ It is also significantly higher than the $27.2 \%$ prevalence in a study covering 47 countries. ${ }^{6}$ Furthermore, the prevalence observed in this study was higher than the $28.0 \%$ reported in a global meta-analysis among medical students ${ }^{60}$ and the $30.6 \%$ reported in Cameroon, Africa. ${ }^{11}$ However, it was lower than the $65 \%$ reported in $\mathrm{Egypt}^{61}$ and $66.8 \%$ in Liaoning province, China. ${ }^{19}$ Overall, medical students from China have a higher prevalence of depression than those from other parts of the world. In this study, most medical students were sophomores, fourth to fifth years, or postgraduates; the high prevalence of depression in this group may be attributable to a few reasons. From sophomore year onward, medical students have heavier academic loads, and competition among students becomes fiercer, while during the fourth to fifth and postgraduate years, students must focus on learning and clinical practice at the same time.$^{62}$ For example, one study showed that exposure to patients' suffering and death was associated with higher levels of depression and anxiety in medical students. ${ }^{63}$

\section{Social support and healthy lifestyles}

The participants' average social support score was $38.06 \pm 7.52$, which is similar to the social support score (38.29 \pm 4.37$)$ among female college students previously reported in China ${ }^{64}$ and at upper middle level of the total score. The objective support score was relatively low, accounting for only $0.39 \%$ of the total score, which signifies that the objective social support available to Chinese college students is generally low. Both

Table 4 Relationship between Zung SDS scores and factor and total scores on the SSRS and HPLP-II

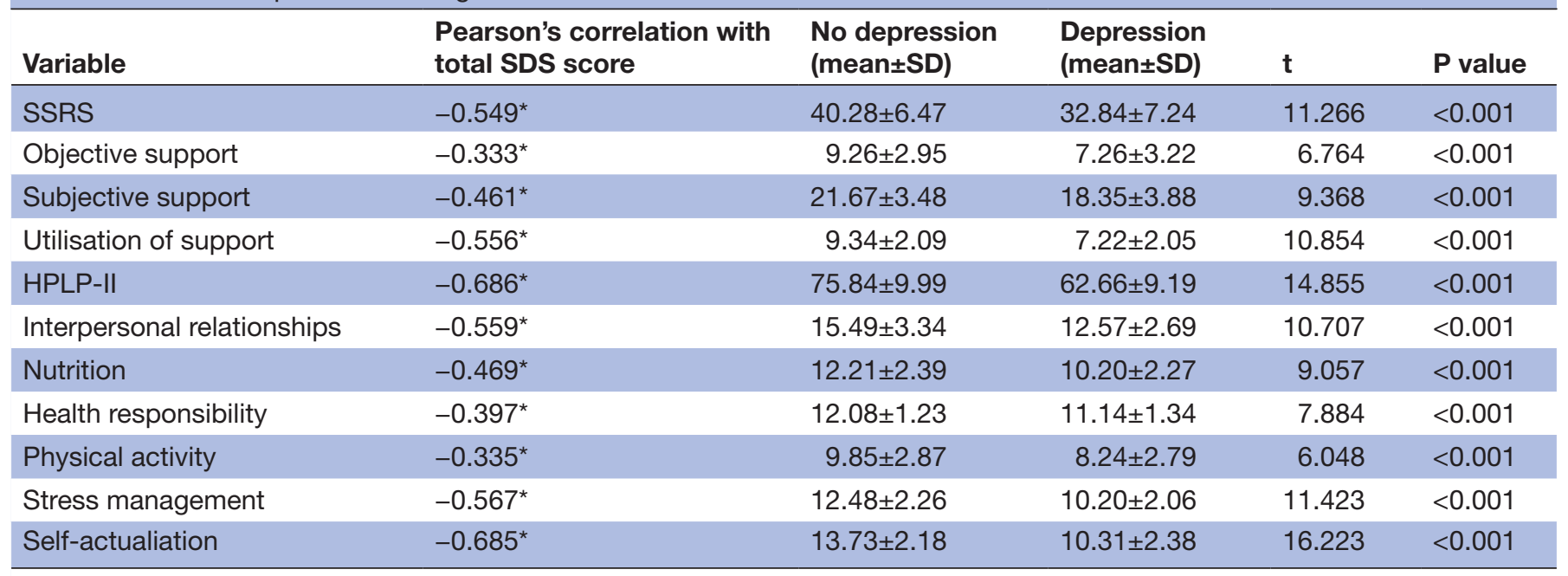

*Significant at the 0.01 level (two-tailed).

HPLP-II, Health-Promoting Lifestyle Profile-II; SDS, Self-Rating Depression Scale; SSRS, Social Support Rating Scale. 
Table 5 Results of the logistic regression analysis for correlates of depression

\begin{tabular}{lcccrr}
\hline Variables & $\boldsymbol{\beta}$ & Waldc ${ }^{2}$ & P value & OR & OR (95\% Cl) \\
\hline Gender (women:men) & 0.96 & 12.709 & $<0.001$ & 2.613 & 0.912 \\
Social support & -0.092 & 21.574 & $<0.001$ & 0.841 to 4.43 \\
Nutrition & -0.139 & 5.528 & $<0.001$ & 0.775 to 0.977 \\
Self-actualisation & -0.441 & 54.017 & $<0.001$ & 0.948 \\
Constant & 8.766 & 86.57 & $<0.001$ & 6413.893 \\
\hline
\end{tabular}

the total score and the diverse factors of social support had a negative correlation with depression and depression trends $(\mathrm{p}<0.01)$, which again revealed that minimal family support, poor interpersonal relationships with companions, lack of emotional support, inadequate utilisation of support, and negative interactions gradually affect psychological perception, and, in turn, develop into depressive symptoms. ${ }^{18} 30$

The results of this questionnaire survey showed that the proportion of psychological counsellors as a source of comfort and concern is low, with only 21 participants $(3.9 \%)$. According to a study of Chinese international students in the $\mathrm{USA}^{65}$ this population is more likely to experience psychological health problems than others, and most of them never seek professional psychological help. Many studies have shown that this scenario is tightly correlated with the prevalent perception in China, that hardships are meant to be endured and psychological health problems are not diseases; thus, patients may feel embarrassed when seeking help. ${ }^{66} 67$ Consequently, people tend to suppress their emotions. In view of this situation, it is necessary to strengthen the attention paid to students' psychology in both Chinese families and school education, treat psychological health problems correctly, and encourage students to communicate and seek help actively.

The average score of health-promoting lifestyles was relatively high $(71.91 \pm 11.47)$. However, among the six subscales, the average score of physical activity was low, accounting for only $59 \%$ of the total score. With the continuous improvement of material living standards and technological advancements, contemporary college students have shown a declining annual trend in terms of exercise. Since physical activity influences psychological health, ${ }^{68-71}$ physical education at universities should focus on improving students' physical condition. In addition, the total and individual factor scores of healthpromoting lifestyles were negatively correlated with depression and depression trends $(\mathrm{p}<0.01)$, which is consistent with the results of a foreign study, that is, healthy behaviour is related to depression, although the scale used was different. ${ }^{41}$

\section{Factors associated with depression}

In the multivariate analysis, being a woman, inadequate social support, poor nutrition and failing to experience selfactualisation were independent risk factors for depression. It was shown that college students' depression is independently related to unhealthy nutritional habits, and strengthening healthy daily routines and dietary habits can lower their depression risk. The failure to experience self-actualisation observed in this study could have been associated with an inherent problem with Chinese education, which is that it is not in touch with the social reality. Most students, who do not understand the concrete, substantive correlation between learning and their future work and lives, have no long-term objectives and are relatively blind to the future, which, in turn, breeds anxiety and depression. Therefore, it is necessary to advocate quality-oriented education, create social practice opportunities and associate education with practice in universities.

Furthermore, studies have shown that school-based prevention programmes have the potential to reduce mental health burden and advance positive public health outcomes. ${ }^{72}$ In view of the risk factors confirmed by this study, we have several suggestions to offer. First, schools should provide compulsory mental health education courses and ensure the quality of psychological education. Second, there is a need to organise a variety of campus and social activities concerning psychological education, encouraging men and women to cooperate with each other. Third, university psychological counselling centres should improve the psychological counselling services on offer, conduct regular schoolwide psychological screening, strengthen the psychological crisis prevention and intervention mechanism, establish the 'fourlevel' prevention system of schools, departments, classes and dormitories, and focus on students with low socioeconomic status and insufficient social support. Specific intervention measures include interpersonal counselling, ${ }^{73}$ positive group psychotherapy ${ }^{74}$ and sports interventions. ${ }^{75}$ Finally, there is a need to gradually establish an effective system of psychological crisis prevention, intervention, referral to medical institutions and rehabilitation to ensure the early detection, early treatment and early rehabilitation of patients with depression. The practical significance of this study is that the results and suggested intervention measures can be submitted to university administrators and psychological counselling services to guide measures to promote college students' mental health.

\section{Limitations}

This study has the following shortcomings. First is the small sample recruited from a single institution, which hinders the generalisability of the results. Second is an inherent limitation of cross-sectional studies, that is, the inability to make causal inferences regarding risk factors and diseases where these exist concurrently. Third, if the sample had included individuals from other important areas, such as the sociology department, the discussion of social factors would have been more in-depth. Finally, our investigation was confined only to depression, and other psychological problems common 
among college students (eg, anxiety) were not included. In future research, it will be necessary to adopt the principle of positive psychology to examine and help change college students' mentality and behavioural habits.

\section{CONCLUSIONS}

According to our study, $29.8 \%$ of college students experienced depressive symptoms, and their social support and healthy lifestyles were at the middle-upper and good levels, respectively. Female college students with an inadequate social support and poor nutritional habits who feel no selfactualisation are most easily affected by depression.

Contributors ZT: designed the study and drafted the manuscript. JL: collected, cleaned and verified the data. ZT and SF: analysed the data, contributed to the interpretation of the results and the critical revision of the manuscript for important intellectual content. All authors have read and approved the final manuscript.

Funding The authors have not declared a specific grant for this research from any funding agency in the public, commercial or not-for-profit sectors.

\section{Competing interests None declared.}

Patient and public involvement Patients and/or the public were not involved in the design, or conduct, or reporting, or dissemination plans of this research.

Patient consent for publication Not required.

Ethics approval The study was approved by the Medical Ethics Committee of the First Affiliated Hospital of University of South China. The consent form was at the beginning of the questionnaire; once the participants had signed the consent form, they moved on to answering the questions. No identifying details were collected.

Provenance and peer review Not commissioned; externally peer reviewed.

Data availability statement All data relevant to the study are included in the article or uploaded as supplementary information. № additional data are available.

Open access This is an open access article distributed in accordance with the Creative Commons Attribution Non Commercial (CC BY-NC 4.0) license, which permits others to distribute, remix, adapt, build upon this work non-commercially, and license their derivative works on different terms, provided the original work is properly cited, appropriate credit is given, any changes made indicated, and the use is non-commercial. See: http://creativecommons.org/licenses/by-nc/4.0/.

ORCID iD

Zaili Tang http://orcid.org/0000-0002-9846-9290

\section{REFERENCES}

1 WONG EH, WIEST DJ. Adolescent depression: links to academic coping and perceived autonomy support. Education 1999;119:668.

2 Depression and other common mental disorders, global health estimates: World Health organization. Department/Division 2017.

3 Pedrelli P, Borsari B, Lipson SK, et al. Gender differences in the relationships among major depressive disorder, heavy alcohol use, and mental health treatment engagement among college students. $J$ Stud Alcohol Drugs 2016;77:620-8.

4 Polanka BM, Vrany EA, Patel J, et al. Depressive disorder subtypes as predictors of incident obesity in US adults: moderation by race/ ethnicity. Am J Epidemiol 2017;185:734-42.

5 Gao R, Tao F-biao, Hu C-lai, et al. [Impact of psychosocial factors on suicide attempts in high school and college students, data from eight cities of China]. Zhonghua Liu Xing Bing Xue Za Zhi 2010;31:9-13.

6 Rotenstein LS, Ramos MA, Torre M, et al. Prevalence of depression, depressive symptoms, and suicidal ideation among medical students: a systematic review and meta-analysis. JAMA 2016;316:2214-36.

7 Lam RW, Mclntosh D, Wang J, et al. Canadian network for mood and anxiety treatments (CANMAT) 2016 clinical guidelines for the management of adults with major depressive disorder: section 1. disease burden and principles of care. Can J Psychiatry 2016;61:510-23.
8 Salo KI, Scharfen J, Wilden ID, et al. Confining the concept of vascular depression to late-onset depression: a meta-analysis of MRI-defined hyperintensity burden in major depressive disorder and bipolar disorder. Front Psychol 2019;10:1241.

9 Ferrari AJ, Charlson FJ, Norman RE, et al. Burden of depressive disorders by country, sex, age, and year: findings from the global burden of disease study 2010. PLoS Med 2013;10:e1001547.

10 Sokratous S, Merkouris A, Middleton N, et al. The prevalence and socio-demographic correlates of depressive symptoms among Cypriot university students: a cross-sectional descriptive corelational study. BMC Psychiatry 2014;14:235.

11 Ngasa SN, Sama C-B, Dzekem BS, et al. Prevalence and factors associated with depression among medical students in Cameroon: a cross-sectional study. BMC Psychiatry 2017;17:216.

12 Dun Y, Ripley-Gonzalez JW, Zhou N, et al. The association between prior physical fitness and depression in young adults during the COVID-19 pandemic-a cross-sectional, retrospective study. PeerJ 2021;9:e11091.

13 Zhang K, Peng Y, Zhang X, et al. Psychological burden and experiences following exposure to COVID-19: a qualitative and quantitative study of Chinese medical student volunteers. Int $J$ Environ Res Public Health 2021;18:4089.

14 Deng J, Zhou F, Hou W, et al. The prevalence of depressive symptoms, anxiety symptoms and sleep disturbance in higher education students during the COVID-19 pandemic: a systematic review and meta-analysis. Psychiatry Res 2021;301:113863.

15 Meeks K, Peak AS, Dreihaus A. Depression, anxiety, and stress among students, faculty, and staff. J Am Coll Health 2021:1-7.

16 Yang $\mathrm{X}, \mathrm{Hu} \mathrm{H}$, Zhao $\mathrm{C}$, et al. A longitudinal study of changes in smart phone addiction and depressive symptoms and potential risk factors among Chinese college students. BMC Psychiatry 2021;21:252.

17 Chen L, Wang L, Quiu XH, et al. Depression among Chinese university students: prevalence and socio-demographic correlates. PLoS One 2013;8:e58379.

18 Schuster TL, Kessler RC, Aseltine RH. Supportive interactions, negative interactions, and depressed mood. Am J Community Psychol 1990;18:423-38.

19 Shi M, Liu L, Wang ZY, et al. Prevalence of depressive symptoms and its correlations with positive psychological variables among Chinese medical students: an exploratory cross-sectional study. BMC Psychiatry 2016;16:3.

20 Sun L, Sun L-N, Sun Y-H, et al. Correlations between psychological symptoms and social relationships among medical undergraduates in Anhui Province of China. Int J Psychiatry Med 2011;42:29-47.

21 Hawkins WE, Tan PP, Hawkins MJ, et al. Depressive symptomatology and specificity of social support. Psychol Rep 1999;84:1180-6.

22 Horgan A, Sweeney J, Behan L, et al. Depressive symptoms, College adjustment and peer support among undergraduate nursing and midwifery students. J Adv Nurs 2016;72:3081-92.

23 Khallad Y, Jabr F. Effects of perceived social support and family demands on college students' mental well-being: a cross-cultura investigation. Int J Psychol 2016;51:348-55.

24 Rueger SY, Chen P, Jenkins LN, et al. Effects of perceived support from mothers, fathers, and teachers on depressive symptoms during the transition to middle school. J Youth Adolesc 2014;43:655-70.

25 Shen M, Gao J, Liang Z. Parental migration patterns and risk of depression and anxiety disorder among rural children aged 10-18 years in China: a cross-sectional study. BMJ Open 2015;5:e7802.

26 Nitzsche A, Jung J, Pfaff $\mathrm{H}$, et al. Employees' negative and positive work-home interaction and their association with depressive symptoms. Am J Ind Med 2013;56:590-8.

27 Gariépy G, Honkaniemi H, Quesnel-Vallée A. Social support and protection from depression: systematic review of current findings in Western countries. Br J Psychiatry 2016;209:284-93.

28 House JS, Landis KR, Umberson D. Social relationships and health. Science 1988;241:540-5.

29 Coyne JC, Downey G. Social factors and psychopathology: stress, social support, and coping processes. Annu Rev Psychol 1991;42:401-25.

30 Barger SD, Messerli-Bürgy N, Barth J. Social relationship correlates of major depressive disorder and depressive symptoms in Switzerland: nationally representative cross sectional study. BMC Public Health 2014;14:273.

31 Shao R, He P, Ling B, et al. Prevalence of depression and anxiety and correlations between depression, anxiety, family functioning, social support and coping styles among Chinese medical students. BMC Psychol 2020;8:38.

32 Hua Y, Wang B, Wallen GR, et al. Health-Promoting lifestyles and depression in urban elderly Chinese. PLoS One 2015;10:e117998. 
33 Global health risks. Mortality and burden of disease attributable to selected major risks. World Health Organization: World Health Organization, Department/Division, 2009.

34 Kang SW, Yoo JS. Health-Promoting lifestyle and depression in metabolic syndrome patients in Korea. Int $J$ Nurs Pract 2012;18:268-74.

35 Tabrizi FM. Health promoting behavior and influencing factors in Iranian breast cancer survivors. Asian Pac J Cancer Prev 2015;16:1729-36.

36 Chen C-M, Kuo S-F, Chou Y-H, et al. Postpartum Taiwanese women: their postpartum depression, social support and health-promoting lifestyle profiles. J Clin Nurs 2007;16:1550-60.

37 Chang C-F, Lin M-H, Wang J, et al. The relationship between geriatric depression and health-promoting behaviors among communitydwelling seniors. J Nurs Res 2013;21:75-82.

38 Hoying J, Melnyk BM, Hutson E, et al. Prevalence and correlates of depression, anxiety, stress, healthy beliefs, and lifestyle behaviors in first-year graduate health sciences students. Worldviews Evid Based Nurs 2020;17:49-59.

39 Yang SY, SH F, Chen KL, et al. Relationships between depression, health-related behaviors, and Internet addiction in female junior college students. PLoS One. 2019;14:e220784.

40 Lazarevich I, Irigoyen Camacho ME, Velázquez-Alva MC, et al. Depression and food consumption in Mexican college students. Nutr Hosp 2018;35:620-6.

41 Allgöwer A, Wardle J, Steptoe A. Depressive symptoms, social support, and personal health behaviors in young men and women. Health Psychol 2001;20:223-7.

42 Schorr AV, Yehuda I, Tamir S. Ethnic differences in loneliness, depression, and malnutrition among older adults during COVID-19 quarantine. J Nutr Health Aging 2021;25:311-7.

43 Patel N, Ferrer HB, Tyrer F, et al. Barriers and facilitators to healthy lifestyle changes in minority ethnic populations in the UK: a narrative review. J Racial Ethn Health Disparities 2017;4:1107-19.

44 Wang M, Liu J, Wu X. The prevalence of depression among students in Chinese universities over the past decade: a meta-analysis. Journal of Hainan Medical University 2020;9:686-93.

$45 \mathrm{Xu} \mathrm{Y,} \mathrm{Qi} \mathrm{J,} \mathrm{Yang} \mathrm{Y,} \mathrm{et} \mathrm{al.} \mathrm{The} \mathrm{contribution} \mathrm{of} \mathrm{lifestyle} \mathrm{factors} \mathrm{to}$ depressive symptoms: a cross-sectional study in Chinese college students. Psychiatry Res 2016;245:243-9.

46 Zung WWK. A self-rating depression scale. Arch Gen Psychiatry 1965;12:63-70.

47 Lee HC, Chiu HF, Wing YK, et al. The Zung self-rating depression scale: screening for depression among the Hong Kong Chinese elderly. J Geriatr Psychiatry Neurol 1994;7:216-20.

48 Chen I-H, Lin C-Y, Zheng X, et al. Assessing Mental Health for China's Police: Psychometric Features of the Self-Rating Depression Scale and Symptom Checklist 90-Revised. Int J Environ Res Public Health 2020;17:2737.

49 Nie J, Zhang W, Liu Y. Exploring depression, self-esteem and verbal fluency with different degrees of Internet addiction among Chinese college students. Compr Psychiatry 2017;72:114-20.

50 Xiao S. Study on the theories and application of the social support rating scale. J Clin Psychol Med 1999;4:98-100.

51 Walker SN, Sechrist KR, Pender NJ. Lifestyle profile II. Omaha: College of Nursing, University of Nebraska Medical Center, 1995

52 Kamali ASMA, Sadeghi R, Tol A, et al. Reliability and validity of Kurdish language version of health promoting lifestyle profile II among Kurdish healthcare providers Kurdish version of HPLP-II. Arch Iran Med 2016;19:824-31.

53 Tajik M, Galvão HM, Eduardo Siqueira C. Health survey instrument development through a community-based participatory research approach: health promoting lifestyle profile (HPLP-II) and Brazilian immigrants in greater Boston. J Immigr Minor Health 2010;12:390-7.

54 Dashtidehkordi A, Shahgholian N, Attari F. Exercise during hemodialysis and health promoting behaviors: a clinical trial. BMC Nephrol 2019;20:96
55 Beiter R, Nash R, McCrady M, et al. The prevalence and correlates of depression, anxiety, and stress in a sample of college students. J Affect Disord 2015;173:90-6.

56 Lei X-Y, Xiao L-M, Liu Y-N, et al. Prevalence of depression among Chinese university students: a meta-analysis. PLoS One 2016;11:e153454.

57 Salk RH, Hyde JS, Abramson LY. Gender differences in depression in representative national samples: meta-analyses of diagnoses and symptoms. Psychol Bull 2017;143:783-822.

58 Gender equality and women's development in China. Beijing: The State Council Information Office of the People's Republic of China 2015.

59 Mao Y, Zhang N, Liu J, et al. A systematic review of depression and anxiety in medical students in China. BMC Med Educ 2019;19:327.

60 Puthran R, Zhang MWB, Tam WW, et al. Prevalence of depression amongst medical students: a meta-analysis. Med Educ 2016;50:456-68.

61 Fawzy M, Hamed SA. Prevalence of psychological stress, depression and anxiety among medical students in Egypt. Psychiatry Res 2017;255:186-94.

62 Moir F, Yielder J, Sanson J, et al. Depression in medical students: current insights. Adv Med Educ Pract 2018;9:323-33.

63 Thiemann P, Quince T, Benson J, et al. Medical students' death anxiety: severity and association with psychological health and attitudes toward palliative care. J Pain Symptom Manage 2015;50:335-42

64 Wang Y-H, Shi Z-T. The influence of social support on sexual mental health of female college students. Medicine 2018;97:e11525.

65 Zheng K, West-Olatunji CA. Mental health concerns of mainland Chinese international students in the United States: a literature review. VISTAS Online, 2016. Available: https://www.counseling.org/ docs/default-source/vistas/article 20fcbf24f16116603abcacff0000 bee5e7.pdf?sfvrsn=62a9442c_4 [Accessed 05 Jun 2020].

66 Qiu P, Caine ED, Hou F, et al. Depression as seen through the eyes of rural Chinese women: implications for help-seeking and the future of mental health care in China. $J$ Affect Disord 2018;227:38-47.

67 Kim JE, Zane N. Help-Seeking intentions among Asian American and white American students in psychological distress: application of the health belief model. Cultur Divers Ethnic Minor Psychol 2016;22:311-21.

68 Kouloutbani K, Karteroliotis K, Politis A. [The effect of physical activity on dementia]. Psychiatriki 2019;30:142-55.

69 Jin Y, Kim D, Hong H, et al. A long-term exercise intervention reduces depressive symptoms in older Korean women. J Sports Sci Med 2019;18:399-404.

70 Tao K, Liu W, Xiong S, et al. Associations between self-determined motivation, accelerometer-determined physical activity, and quality of life in Chinese college students. Int J Environ Res Public Health 2019;16. doi:10.3390/ijerph16162941. [Epub ahead of print: 1608 2019].

71 Mikkelsen K, Stojanovska L, Polenakovic M, et al. Exercise and mental health. Maturitas 2017:106:48-56.

72 Werner-Seidler A, Perry Y, Calear AL, et al. School-Based depression and anxiety prevention programs for young people: a systematic review and meta-analysis. Clin Psychol Rev 2017;51:30-47

73 Weissman MM, Hankerson SH, Scorza P, et al. Interpersonal counseling (IPC) for depression in primary care. Am J Psychother 2014;68:359-83.

74 Dowlatabadi MM, Ahmadi SM, Sorbi MH, et al. The effectiveness of group positive psychotherapy on depression and happiness in breast cancer patients: a randomized controlled trial. Electron Physician 2016;8:2175-80.

75 Johnston SA, Roskowski C, He Z, et al. Effects of team sports on anxiety, depression, perceived stress, and sleep quality in college students. J Am Coll Health 2020:1-7. 